\title{
AN AUDIT ASSESSMENT OF PREOPERATIVE FASTING FOR ELECTIVE SURGERIES
}

\author{
J. Radhika1 , R. Vasanthageethan'2, P. Kayalvizhi ${ }^{3}$
}

${ }_{1}^{1}$ Assistant Professor, Department of Anaesthesiology, Government Mohan Kumaramangalam Medical College, Salem, Tamilnadu. ${ }^{2}$ Associate Professor, Department of Anaesthesiology, Government Mohan Kumaramangalam Medical College, Salem, Tamilnadu. ${ }^{3}$ Assistant Professor, Department of Anaesthesiology, Government Mohan Kumaramangalam Medical College, Salem, Tamilnadu.

\section{ABSTRACT}

\section{BACKGROUND}

Fasting before elective surgeries is a regularly practiced norm for the past few decades. Preoperative fasting reduces the gastric volume and prevents aspiration during surgery. The guidelines for duration of fasting has been promulgated by the ASA, nevertheless, in practice there are wide discrepancies. This study was done to assess the level of knowledge and practices regarding preoperative fasting among health care providers.

\section{MATERIALS AND METHODS}

The doctors and nurses of surgical departments of our hospital were then taken up for the study. A total of 122 health care providers were included in this cross-sectional study, of which 65 were nurses. A structured self-administered questionnaire was used to collect the data regarding fasting times prior to various anaesthesia and fasting times for different food stuffs.

\section{RESULTS}

The mean duration of fasting for solids was 12 hours and for liquids was 7 hours. Overall, 49\% of the study participants had adequate knowledge on the duration of preoperative fasting. Over 30\% of the participants felt that the duration of fasting can be lowered for various types of anaesthesia.

\section{CONCLUSION}

There is an imminent need for bringing about a change in the attitudes and practices regarding the preoperative fasting among the health care providers. This study has elucidated the role of anaesthetists in pioneering this change by way of creating awareness and monitoring the implementation of the ASA guidelines in health care practice.

\section{KEYWORDS}

Elective Surgery, General Anaesthesia, Preoperative Fasting, Pulmonary Aspiration.

HOW TO CITE THIS ARTICLE: Radhika J, Vasanthageethan R, Kayalvizhi P. An audit assessment of preoperative fasting for elective surgeries. J. Evolution Med. Dent. Sci. 2018;7(05):585-587, DOI: 10.14260/jemds/2018/133

\section{BACKGROUND}

It has been a common practice to prepare patients undergoing elective surgeries with general anaesthesia. Among the several guidelines which include maintenance of blood pressure etc., pre-operative fasting has been an essential procedure. It has been observed that fasting before general anaesthesia reduces the volume and acidity of stomach contents during surgery.[1] The policy varies from 'nil per oral' approach to restricted fluid intake for few hours before surgery. Fasting from midnight was thought to reduce the risk of pulmonary aspiration and regurgitation. An aspiration as little as $30-40 \mathrm{~mL}$ can result in significant complications and even death. Several factors including pregnancy, obesity and difficult airway can predispose to aspiration. This emphasises the need for gastric emptying prior to surgeries. Though, there are several regulatory mechanisms like hormonal, neuronal and metabolic feedback, the assessment of residual gastric volume cannot be taken as a gold standard procedure to determine the risk for aspiration.

'Financial or Other Competing Interest': None.

Submission 20-12-2017, Peer Review 13-01-2018,

Acceptance 19-01-2018, Published 29-01-2018.

Corresponding Author:

Dr. P. Kayalvizhi,

\#236, Seed Colony, Alagapuram,

Salem-636016, Tamilnadu.

E-mail: drkayalanaes@gmail.com

DOI: $10.14260 /$ jemds $/ 2018 / 133$

\section{(c) $(7)$}

For pulmonary aspiration to occur, there could be increased regurgitation as a result of gastro-oesophageal reflex, loss of protective airway reflexes and an increase in gastric volume due to inadequate fasting or late emptying. Of the above mentioned risk factors, gastric volume is the only modifiable risk factor.[2]

It has been universally agreed that pre-operative fasting is a vital procedure to minimise gastric volume; however, the duration of pre-operative fasting has been long departed. The AAGBI, ASA and RCN have given separate recommendation for each type of food. For clear fluids the recommended duration is 2 hours and for breast milk 4 hours; for infant formula, non-human milk and light meal the recommended duration of fasting is 6 hours. When the surgery is scheduled in the morning, the patients are refrained from food intake after midnight. They are encouraged to drink either water or juice at 6 am. No drinks are allowed after 6 am. For surgeries which are scheduled in the afternoon, a light breakfast in the form of bread toast or cereal is allowed up to $7 \mathrm{am}$. Drinks like water or juice may be encouraged up to $11 \mathrm{am}$. No milk or milk containing drinks are permitted on the day of surgery.[3]

It is important that the Doctors and the health care team taking care of the patients undergoing surgeries are aware of these guidelines. The study done by Gunawarthana SAAI showed that the mean duration of fasting was 13.86 hours for solids and 12.68 hours for liquids. A satisfactory level of knowledge was observed in $64.34 \%$ of interns and medical officers.[4] A study done by Ossama Hammdy Salman showed 
the tradition that MPO after midnight was still practiced among $72.3 \%$ of practitioners.[5] Prolonged duration of preoperative fasting is associated with several complications and risks. The psychosocial impact includes confusion, irritability and social isolation of missing a meal. The physiological impact consists of dehydration, headaches, hypoglycaemia and electrolyte imbalance and vomiting. The study done by Garge Njoroge showed that $29.2 \%$ of the patients developed anxiety due to prolonged duration of fasting.[6]

\section{Objectives}

1. To access the knowledge regarding preoperative fasting guidelines.

2. To evaluate the preoperative fasting practices employed in our hospital.

\section{MATERIALS AND METHODS}

\section{Study Setting}

This study was carried out as a cross-sectional study among the health care providers and patients admitted in our tertiary care hospital in Salem district.

\section{Study Population}

The doctors and nurses of surgical departments of our hospital were then taken up for the study. Based on a study done by $\mathrm{OH}$ Salman, $62.6 \%$ of the health care providers had knowledge regarding pre-operative guidelines.[5] At 95\% level of significance and $9 \%$ absolute precision, a sample size calculated was 110.9 . Accounting $10 \%$ for non-response, the final sample size was calculated 121.9 and was rounded off to 122. Our hospital consists of 250 surgical staffs, of which 100 were doctors and 150 were nursing staffs. A single list consisting of all the 250 staffs were prepared, from which 122 participants were selected by simple random sampling using computer generated random numbers.

\section{Selection Criteria}

Doctors and nurses who belonged to surgical department and who consented for the study were included.

\section{Data Collection}

A structured self-administered questionnaire was used to collect the data regarding fasting times prior to various anaesthesia and fasting times for different food stuffs. The data regarding fasting practices followed by the health care providers were also elicited.

\section{Data Analysis}

Data was entered and analysed using Microsoft Excel Spreadsheet, mean duration of fasting and information regarding knowledge and practices were expressed in percentages.

\section{RESULTS}

This study is a cross-sectional study among 120 health care providers of our criteria care hospital. A total of 65 nurses and 57 doctors participated in the studies. The mean duration of fasting for solids was 12 hours and for liquids was 7 hours. The prevalence of adequate knowledge regarding duration of fasting for different food stuffs is given in Table 1. Overall, $49 \%$ of the participants had adequate knowledge regarding the duration of fasting.

\begin{tabular}{|c|c|c|c|c|c|}
\hline \multirow{2}{*}{$\begin{array}{c}\text { Sl. } \\
\text { No. }\end{array}$} & \multirow{2}{*}{ Food Stuff } & \multicolumn{2}{|c|}{ Doctors } & \multicolumn{2}{c|}{ Nurses } \\
\cline { 3 - 6 } & N= 57 & $\mathbf{\%}^{*}$ & N= 65 & $\%^{*}$ \\
\hline $\mathbf{1}$ & Large meal & 7 & 12.3 & 21 & 32.3 \\
\hline $\mathbf{2}$ & Slice of toast & 48 & 84.2 & 44 & 67.7 \\
\hline $\mathbf{3}$ & Tea/coffee/milk & 50 & 87.72 & 54 & 83.08 \\
\hline $\mathbf{4}$ & Breast milk & 23 & 40.35 & 23 & 35.38 \\
\hline $\mathbf{5}$ & Clear fluids & 43 & 75.44 & 33 & 50.76 \\
\hline $\mathbf{6}$ & $\begin{array}{c}\text { Tablets with } \\
\text { water }\end{array}$ & 15 & 26.31 & 23 & 35.38 \\
\hline $\mathbf{7}$ & Chewing gum & 15 & 26.31 & 12 & 18.46 \\
\hline \multicolumn{3}{|c|}{ Table 1. Prevalence of Adequate Knowledge regarding } \\
Duration of Fasting for Different Food Stuffs \\
\hline
\end{tabular}

*Percentages will not total to 100.

The opinion regarding minimum duration of fasting prior to sedation is given in Table 2. In comparison with the existing guidelines $18 \%$ of the doctors, $38 \%$ nurses felt that duration should be shorter. About $11 \%$ of the nurses and $3 \%$ of the doctors felt that there was no need for pre-operative fasting.

\begin{tabular}{|c|c|c|c|c|c|}
\hline \multirow[b]{2}{*}{$\begin{array}{l}\text { Sl. } \\
\text { No. }\end{array}$} & \multirow{2}{*}{$\begin{array}{c}\text { Fasting } \\
\text { Prior to } \\
\text { Sedation } \\
\text { should be }\end{array}$} & \multicolumn{2}{|c|}{ Doctors } & \multicolumn{2}{|c|}{ Nurses } \\
\hline & & Frequency & $\%$ & Frequency & $\%$ \\
\hline 1 & Longer & 8 & 14 & 13 & 20 \\
\hline 2 & Same & 36 & 63 & 19 & 29 \\
\hline 3 & Shorter & 10 & 18 & 25 & 38 \\
\hline 4 & No fasting & 2 & 3 & 7 & 11 \\
\hline 5 & Nil & 1 & 2 & 1 & 2 \\
\hline & $\begin{array}{r}\text { Table 2. Opi } \\
\text { of }\end{array}$ & sting Prio & Mi & $\begin{array}{l}\text { um Dura } \\
\text { tion }\end{array}$ & \\
\hline
\end{tabular}

The opinion regarding minimum duration of fasting prior to spinal anaesthesia is given in Table 3 . In comparison with the existing guidelines $18 \%$ of the doctors, $11 \%$ nurses felt that duration should be shorter. About $2 \%$ of the nurses and doctors felt that there was no need for pre-operative fasting.

\begin{tabular}{|c|c|c|c|c|c|}
\hline \multirow{2}{*}{$\begin{array}{l}\text { Sl. } \\
\text { No. }\end{array}$} & \multirow{2}{*}{$\begin{array}{c}\text { Fasting Prior } \\
\text { to Spinal } \\
\text { Anaesthesia }\end{array}$} & \multicolumn{2}{|c|}{ Doctors } & \multicolumn{2}{|c|}{ Nurses } \\
\hline & & Frequency & $\%$ & Frequency & $\%$ \\
\hline 1 & Longer & 2 & 4 & 41 & 63 \\
\hline 2 & The same & 42 & 74 & 16 & 25 \\
\hline 3 & Shorter & 10 & 18 & 7 & 11 \\
\hline 4 & No fasting & 1 & 2 & 1 & 2 \\
\hline
\end{tabular}

Table 3. Opinion regarding Minimum Duration of Fasting prior to Spinal Anaesthesia

The opinion regarding minimum duration of fasting prior to local anaesthesia is given in Table 4 . About $60 \%$ of the nurses and $77 \%$ of the doctors felt that there was no need for pre-operative fasting.

\begin{tabular}{|c|c|c|c|c|c|}
\hline \multirow{2}{*}{$\begin{array}{c}\text { Sl. } \\
\text { No. }\end{array}$} & Fasting Prior & \multicolumn{2}{|c|}{ Doctors } & \multicolumn{2}{|c|}{ Nurses } \\
\cline { 3 - 6 } & Anaesthesia & Frequency & $\mathbf{\%}$ & Frequency & $\mathbf{\%}$ \\
\hline $\mathbf{1}$ & 2 hours & 3 & 5 & 10 & 15 \\
\hline $\mathbf{2}$ & 6 hours & 8 & 14 & 12 & 18 \\
\hline $\mathbf{3}$ & No fasting & 44 & 77 & 39 & 60 \\
\hline $\mathbf{4}$ & $\begin{array}{c}\text { None of the } \\
\text { above }\end{array}$ & 2 & 4 & 4 & 6 \\
\hline
\end{tabular}

Table 4. The Knowledge regarding Minimum Duration of Fasting prior to Local Anaesthesia 
The knowledge regarding definition of clear fluids was assessed and is given in Table 5 . About $2 \%$ of the doctors and $28 \%$ of the nurses felt that milk is a clear fluid. Similarly, $38.5 \%$ of the doctors and $28 \%$ of the nurses believed that tea and coffee are clear fluids.

\begin{tabular}{|c|c|c|c|c|c|}
\hline Sl. & Name of the & \multicolumn{2}{|c|}{ Doctors } & \multicolumn{2}{c|}{ Nurses } \\
\cline { 3 - 6 } No. & Clear Fluids & Frequency & \% & Frequency & \% \\
\hline $\mathbf{1}$ & Water & 56 & 98 & 63 & 97 \\
\hline $\mathbf{2}$ & Squash & 3 & 5 & 4 & 6 \\
\hline $\mathbf{3}$ & Lemonade & 27 & 47 & 11 & 17 \\
\hline $\mathbf{4}$ & Milk & 1 & 2 & 18 & 28 \\
\hline $\mathbf{5}$ & $\begin{array}{c}\text { Black Tea/ } \\
\text { Coffee }\end{array}$ & 22 & 38.5 & 18 & 28 \\
\hline $\mathbf{6}$ & $\begin{array}{c}\text { Tea/ Coffee } \\
\text { with Milk }\end{array}$ & 0 & 0 & 2 & 3 \\
\hline \multicolumn{7}{|c|}{ Table 5. Knowledge regarding the Definition of Clear } \\
Fluids
\end{tabular}

The practices regarding duration of fasting for solids and liquids are given in Table 6. In 39\% of the patients, fasting for solids was advised between 6 - 10 hours and in $17 \%$ of the patients 6 - 10 hours of fasting was advised for liquids.

\begin{tabular}{|c|c|c|c|c|c|}
\hline Sl. & Fasting & \multicolumn{2}{|c|}{ Solid } & \multicolumn{2}{c|}{ Liquid } \\
\cline { 3 - 6 } No. & Hours & Frequency & $\mathbf{\%}$ & Frequency & $\mathbf{\%}$ \\
\hline $\mathbf{1}$ & $6-10$ & 52 & 39 & 23 & 17 \\
\hline $\mathbf{2}$ & $10-14$ & 47 & 35 & 6 & 4 \\
\hline $\mathbf{3}$ & $14-18$ & 30 & 22 & 0 & 0 \\
\hline $\mathbf{4}$ & $>18$ & 6 & 4 & 0 & 0 \\
\hline \multicolumn{3}{|c}{ Table 6. Duration of Fasting for Solids and Liquids } \\
\hline
\end{tabular}

\section{DISCUSSION}

This study elucidates the need for emphasising the guidelines for pre-operative fasting. Although, the first International pre-operative fasting recommendations was published ASA in 1999. The knowledge regarding these were not disseminated to surgeons or other health care providers. Moreover, several studies have shown a reduced compliance among anaesthetist fraternity.

Our study showed a mean of 12 hours fasting for solids of 7 hours fasting for liquids. A study done by Gunawardhana showed similar results.[4] In a study done by Abebe et al, the mean duration of fasting was 15.9 and 15.3 hours for solids and liquids respectively, which was higher than our study.[7] In a study done by Gebremendhn EG et al, the mean duration was even higher, being 19.6 hours. ${ }^{[8]}$

Although, the guidelines recommend pre-operative clear fluid intake 2 hours prior to the surgery, the knowledge regarding the definition of clean fluids was lacking among the study participants. Studies have shown discrepancies in the instructions given by anaesthetists and the implementation of this instruction by the nurses in the wards. Several studies have documented the incorrect use of oral fluids prior to the surgery.
In this study, the knowledge/ opinion regarding the duration of anaesthesia for various types of anaesthesia was well analysed. While a majority of the doctors agreed in the existing guidelines, a considerable segment believed in lowering the duration. A sequential analysis in concurrence with the patient's response parameters will give an insight regarding these recommendations.

\section{CONCLUSION}

The role of anaesthetist in implementation of the ASA guidelines is larger in the existing scenario. It is essential to create awareness by providing information and education in these practice guidelines to the health care team of the hospitals. The anaesthetists' team should aim at achieving a change in the behaviour through effective communication. This may be done by fixtures, flyers and posters in the wards, display of audit results in the OTs and conducting periodic checks assessments by interrogation with the patients.

\section{REFERENCES}

[1] Brady M, Kinn S, Stuart P. Preoperative fasting for adults to prevent perioperative complications. Cochrane Database Syst Rev 2003;(4):CD004423.

[2] Mesbah A, Thomas M. Preoperative fasting in children. BJA Education 2017;17(10):346-50.

[3] American Society of Anesthesiologists Committee. Practice guidelines for preoperative fasting and the use of pharmacologic agents to reduce the risk of pulmonary aspiration: an updated report by the American Society of Anesthesiologists Committee on Standards and Practice Parameters. Anaesthesiology 2011;114(3):495-511.

[4] Gunawardhana SAAI. Knowledge, attitudes and practice of preoperative fasting guidelines in the national hospital of Sri Lanka. Sri Lankan Journal of Anaesthesiology 2012;20(2):92-5.

[5] Salman OH, Asida SM, Ali HS. Current knowledge, practice and attitude of preoperative fasting: a limited survey among Upper Egypt anesthetists. Egyptian Journal of Anaesthesia 2013;29(2):125-30.

[6] Njoroge G, Kivuti-Bitok L, Kimani S. Preoperative fasting among adult patients for elective surgery in a Kenyan referral hospital. Article ID 2159606, International Scholarly Research Notices 2017;2017: p. 8.

[7] Abebe WA, Rukewe A, Bekele NA, et al. Preoperative fasting times in elective surgical patients at a referral hospital in Botswana. Pan Afr Med J 2016;23:102.

[8] Gebremendhn EG, Nagaratnam VB. Audit on preoperative fasting of elective surgical patients in an African Academic Medical Center. World J Surg 2014;38(9):2200-04. 